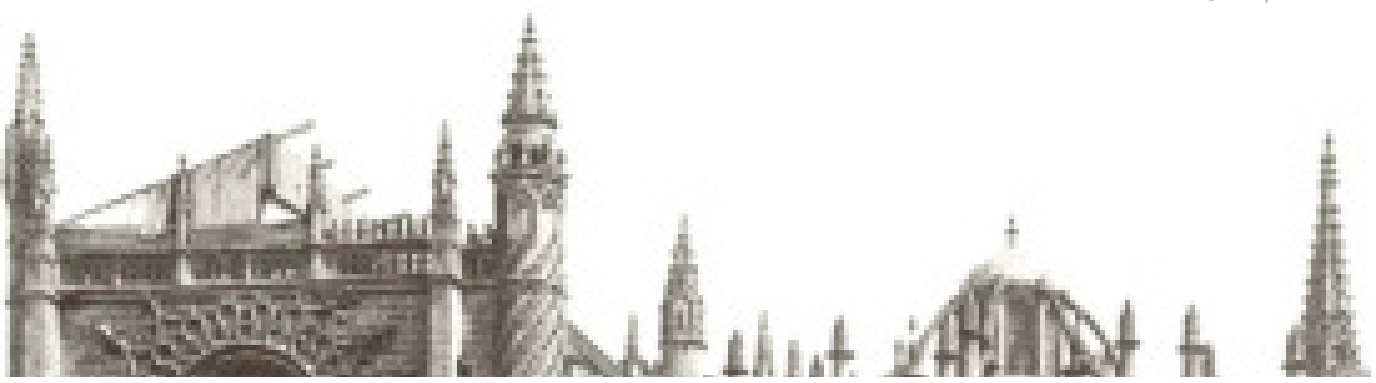

\title{
Conservation to overcome oblivion. New methods for the survival of lost heritage memory
}

\author{
María José Merchán, Emiliano Pérez
}

\begin{abstract}
Unfortunately, it sometimes happens that heritage buildings and structures unearthed during the construction of new infrastructures cannot be adequately conserved once dug out. Before the eternal doubt, keeping or covering them, the economic aspect often takes precedence. Luckily, when the decision is to hide it again, technology offers the possibility of acquiring, modelling and storing the 3D data of the remains and allows their later visualization with a very realistic appearance. Therefore, the memory of these remains destined to be forgotten survives beyond the archives of the professionals who documented them. In this paper, the opportunities opened by Augmented and Virtual Reality applications for the preservation and dissemination of re-covered, or even lost, remains will be explained through the finding came about in the works performed for renovating an old road in Fuente del Maestre (Spain).
\end{abstract}

Keywords: conservation, cultural heritage, 3D modelling, augmented/virtual reality

\section{Conservación para superar el olvido. Nuevos métodos para la supervivencia de la memoria del patrimonio perdido}

Resumen: A veces sucede que, desafortunadamente, los edificios históricos desenterrados durante la construcción de nuevas infraestructuras no pueden conservarse adecuadamente una vez excavados. Ante la eterna duda, mantenerlos o cubrirlos, el aspecto económico muy a menudo tiene prioridad. Por suerte, cuando la decisión es ocultarlo nuevamente, la tecnología ofrece la posibilidad de adquirir, modelar y almacenar los datos 3D de los restos para su posterior visualización de forma muy realista. De esta manera, el recuerdo de estos restos destinados a ser olvidados sobrevive más allá de los archivos de los profesionales que los documentaron. En este documento, las oportunidades que se abren gracias a la Realidad Aumentada y la Realidad Virtual aplicadas a la preservación y difusión de aquellos restos que deben ser enterrados de nuevo y que, incluso, llegan a perderse, se explicarán a través del hallazgo que se produjo en los trabajos realizados para renovar una antigua carretera en Fuente del Maestre (España).

Palabras clave: conservación, patrimonio cultural, modelado 3D, realidad aumentada/realidad virtual

\section{Introduction}

Defining what conservation means is a very arduous task. It must be considered from a holistic viewpoint: from culture to society, from identity to management. Thus, giving a definition from one of its aspects implies, necessarily leaving apart the others. Conservation has to do with restoration so tightly that people sometimes mix up both terms. But conserving doesn't always imply restoring. In the same way, conservation is related to preservation in such a way that both are often perceived like synonymous. The ICOM, which assumes this quasi correspondence between the two terms, states: "To preserve means to protect a thing or a group of things from different hazards such as destruction, deterioration, separation or even theft; this protection is ensured by gathering the collection in one place, inventorying it, sheltering it, making it secure and repairing it" (Desvallées \& Mairesse 2010: 65). Preserving to ensure the continuity of things implies the recognition that tomorrow's public is equally important than today's (Castriota 2019: 49).

But nowadays, conservation/preservation goes beyond prolonging the heritage assets' physical lives for the far 
future. Other values, not always tangible, must also be preserved for the coming generations: what they mean for the identity of the people in the surroundings, their relation with the natural environment, besides their historical, artistic, cultural, political, economic or social value (Hölling 2017:87). In order to get to this end, it is essential to maintain the authenticity of the heritage property (ICOMOS 1994), always following the principles of restoration gathered in successive charters along the years (ICOMOS 2004).

Paradoxically, conservation seems even more necessary when the cultural assets are going to disappear. In these cases,"conservation"plays a very important rolein preserving the memory of the heritage for future generations to know it. When the strategy of documenting the cultural property before its disappearance is complemented with wellfocused dissemination activities, this type of conservation could mean economic and social improvements for the population of the area. This is the case tackled in this paper, conservation to overcome the oblivion that, sooner or later, goes irretrievably linked to the disappearance.

On this way towards the safeguarding of cultural heritage, technology has come to help and improve the labour of experts in conservation with new multidisciplinary methods (Cozzani 2017, Zhou 2012). Within the most used scientific techniques applied to the cultural heritage, those related to 3D digitizing and modelling (Tucci et al. 2017; Aicardi et al. 2018; Andreu \& Serrano 2019), as well as the development of Virtual Reality and Augmented Reality applications have already established useful and recognized methodologies (Bekele et al. 2018) to become essential in all the research, documentation and dissemination stages of the conservation procedures nowadays (Ruiz Bazán \& Vita 2017: 208).

Concerning the investigation, the advances produced by these new methods entail a deeper understanding of cultural goods and greater savings in working hours, as well as they also allow real-time monitoring, visualization and intervention without manipulation, since it is a noninvasive/non-destructive technology (Niquet \& MasBarberà 2018: 6). When talking about documentation, the creation of digital repositories of artworks, monuments and sites ensure their survival along the years. Furthermost, linking this idea of "persistence" with the use of technology for dissemination, it must be said that 3D technology applied to cultural heritage is a very effective method for people to know and remember. It allows providing not only a "copy" of the very goods but also an understandable and enjoyable interpretation, far from the unintelligible fragments they can often see in reality. These two last possibilities, documentation and diffusion, are even more relevant whether the archaeological remains have to be covered again and cannot be seen anymore (Tait 2016). This way, in recent years, it has demonstrated to be very useful in cases of destruction associated with war conflicts and catastrophes since 3D digitization together with the digital fabrication (Merchán et al. 2019) are perfect tools for preserving and transmitting the heritage to future generations (Ruiz Torres 2017: 148). To perform the entire task, from documentation to dissemination, the existence of interdisciplinary work teams, composed of humanists and technologists, is necessary to achieve the equilibrium between what has to be shown (historical/artistic/social, etc. meaning) and the way it is (which has to do with the technological resources).

As mentioned, among the experiences based on 3D models used for the dissemination of cultural heritage, Virtual Reality (VR) and Augmented Reality (AR) are the most relevant. Regarding Virtual Reality experiences, two different type of them can be found in literature. On the one hand, some of them use $360^{\circ}$ photos and video tours, with a high potential for disseminating the Heritage, since it is valid for a great range of devices (Argyriou et al. 2020; Mah et al. 2019; Njerekai 2019; Sánchez-Aparicio et al. 2019). On the other hand, other experiences make use of $3 \mathrm{D}$ environment that can be toured in real time but usually need more specific devices to visualize them. It is worth mentioning some initiatives carried out lately for enabling the visualization of pieces, monuments or sites which have unfortunately disappeared (Pérez et al. 2018) or whose bad state of conservation or some other reasons (distance, inaccessible location, etc.), prevent them to be seen/ visited (Pérez et al. 2019). In these cases, VR has proven to be very helpful to bring back this "lost" cultural heritage to people. In spite of this, it is not the most utilized tool when it comes to its dissemination. Firstly, because the viewer's vision is replaced by a virtual world, which makes the real heritage remains happen in a second place. Secondly, the high economic cost of virtual reality equipment must be taken into account. This makes the use of this technology not affordable for many museums, interpretive centres and other cultural institutions.

Regarding Augmented Reality, the most accepted definition is that posed by Azuma (Azuma 1997). He defines an AR system as the one that fulfils all the following properties: (1) combines real and virtual content, (2) in an interactive environment in real-time and (3) is registered in $3 \mathrm{D}$. Unlike VR, the fact that users can visualize added information (virtually created) without losing sight of the main elements of the real world makes the AR applications more suitable to be applied to cultural heritage on most occasions. It is also a more affordable and accessible resource since the most used AR devices are mobile phones or tablets. Hence, the problem of economic cost is overcome. In the last and more sophisticated experiences, the use of specific glasses which do not impede the vision of the "real world" starts to be habitual. They integrate a small screen in the lenses that project the virtual models that must be seen by users. In some of these AR glasses, there are two small screens, one per eye, to create a stereoscopic pair that allows 3D viewing. Likewise, they can also incorporate cameras that analyse the environment to locate the models in a realistic way or that interpret the users' gestures in the case they serve to interact with 
the AR application. Although the cost of these devices is becoming increasingly affordable as they become popular, they are still prohibitively expensive.

In the light of the possibilities offered by this 3D technology for the dissemination of "disappearing" heritage and, thus, for the preservation of its memory, an immersive VR experience and an Augmented Reality application are being developed. Both are designed to allow the users to visit and understand those archaeological sites that are hidden from sight, specifically the one known as "La Matilla" (Fuente del Maestre, Spain), which had to be re-covered by the EX-360 road after its excavation.

This paper presents the procedure followed to create these two applications, for which it was necessary to design a method that allowed merging the 3D data acquired by different devices so that to obtain a unique digital model of the site. The content is structured as follows. Firstly, the site of "La Matilla" and its historical context are described. Secondly, 3D data acquisition and modelling are explained. The next section is devoted to detail the procedure followed to design both applications. Afterwards, future work is outlined. Finally, some conclusions are drawn.

\section{“La Matilla". A multicultural archaeological site}

During the improvement works of the road EX-360, which links the towns of Fuente del Maestre and Villafranca de los Barros (Badajoz, Spain), some archaeological remains were unearthed at the height of the place known as "La Matilla".

Located at the foothills of the Sierra de San Jorge, these findings were not a surprise for experts as the existence of a large water storage pond from the Roman period was known to exist in the surroundings since a long time ago. The width and height of the still visible walls, as well as the dimensions of the pool, made experts think that some type of Roman settlement would exist in this zone. Besides, fragments of sigillata pottery from different epochs (from 1 st to 3rd centuries AD) had been recovered on the surface of the area, reinforcing the idea of a Roman presence in this zone. The importance of the site continued, at least, until the Middle Ages as it is documented the existence of a church of Hispanic-Visigoth origin that survived until the nineteenth century as the hermitage of San Jorge (Pascual 1999: 21).

In spite of this knowledge about the past of this area, when archaeologist arrived there, they just found a diaphanous extension which did not betoken the richness it hid in its subsoil. Thus, employing archaeological methodology, they were able to read the history of the place, from the 20th century remains to those dated in the founding moments of Augusta Emerita. In this process, several historical stages were documented (Arabic, Visigoth and late Roman) to which the silos and burials found during the excavation would correspond.
As for the Roman strata, 9 different ceramic ovens and a badly preserved building were documented. Experts think that inside this building the administrative tasks that the management of this pottery industry entailed would have been carried out [figure 1]. The kilns had been excavated in the ground, made of limestone, which has allowed the conservation of much of these substructures. The construction was made of brick, the same material in which were built some semi-circular arches of perfect execution, which were still visible [figure 2]. In some of these ovens, the upper grate was also fairly well preserved. Archaeological analyses of both the structures and the fragments of pottery recovered in the area have confirmed the useful life of this production centre, which would have been in operation between the 1 st and 2 nd centuries AD (Sánchez González 2019:13-14).

Unfortunately, these remains appeared just under the course of the new road, so the problem of their conservation raised. After proposing several options, most of which meant a considerable increase in time and cost, the political decision was to cover the remains, trying to preserve their integrity as much as possible, according to the recommendation made by the heritage experts at the Junta de Extremadura. However, this meant demolishing the arches so magnificently preserved for centuries. To conserve the memory of the site, the group "3D CO-VIM", belonging to the University of Extremadura, proposed the digitization of the site and the creation of a 3D model that would allow both the researchers and the public to have a realistic digital copy of this missing heritage. This digital

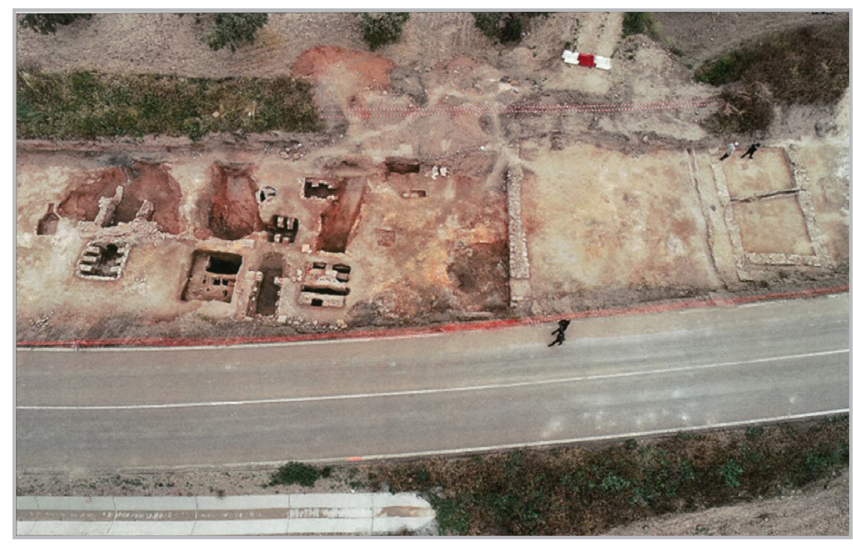

Figure 1.- Aerial photograph of the excavations.
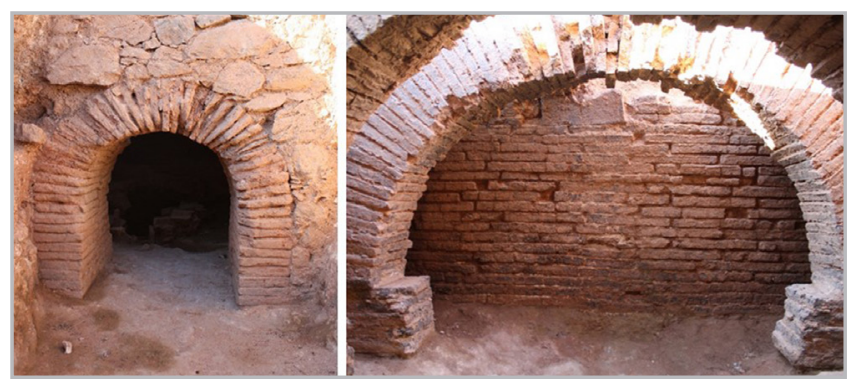

Figure 2.- A) Photo of the entrance to the bigger oven $(\mathrm{H} 2)$ B) Photo of one semi-circular arch belonging to the $\mathrm{H} 1$ oven. 
model would also allow the design and development of some basic AR/VR applications that make possible the visualization of the 3D model.

The procedure followed to reach this goal will be explained in the next sections.

\section{Digitizing and modelling}

\section{Digitization process}

Nowadays, different technologies are available to undertake a digitalization work: laser scanners, structured-light sensors, photogrammetry, etc. When it comes to choosing among them, it is important to consider several aspects: the basic specifications of the devices, the differences between the outcomes provided by each technology, the lighting conditions, the features of the object/building/ space to be digitized and the subsequent use that the acquired data will receive. In this work, we applied the three different technologies we had at our disposal in the acquisition phase: a Faro LS880 Laser-Scanner, an Artec MHT 3D structured-light hand-held scanner and a Nikon D60 digital camera. Technical specifications of the two 3D scanner are summarized in Table 1. Regarding the digital camera, it has a resolution of $10.2 \mathrm{Mpix}$, a sensor size of $23.6 \mathrm{~mm} \times 15.8 \mathrm{~mm}$ and a we used a lens of $3.06 \times \mathrm{zoom} 18-$ $55 \mathrm{~mm}(27-83 \mathrm{~mm}$ eq.).
By using these three options, our aim was not to repeat the digitization process three times but to apply each of them selectively. Based on topology, two different environments could be distinguished in the site: the vast exterior area in which the remains were located and the interior of the two better preserved kilns ( $\mathrm{H} 1$ and $\mathrm{H} 2)$. The differences in the preservation state, space and light conditions imposed the technology to use in each.

Before starting, we were aware that 3D models obtained through the resulting data generated with the laser scanner would be employed only to document the site, whereas the data obtained using the Artec scanner and the Nikon camera would be applied both for documentation and visualization applications. Given that we have used two technologies to digitize the outside zone, the Faro laser scanner and the Nikon camera, we obtained two different resolutions models of that area: the laser scanner generates a higher resolution model and the photogrammetry a medium-low resolution one, both of them textured but with a significant difference in the quality of the textures. The former model is more suitable for documentation because it provides a more precise reconstruction of the real environment, while the latter is more appropriate for visualization applications, which cannot manage very high-resolution models in real-time. Reducing the higher resolution model allows to obtain a medium-low resolution one, obviously at the cost of an elevated time consumption. Moreover, the quality of textures produced by the Faro laser scanner is poorer than

Table 1.- Technical specifications of the 3D scanners employed in the site.

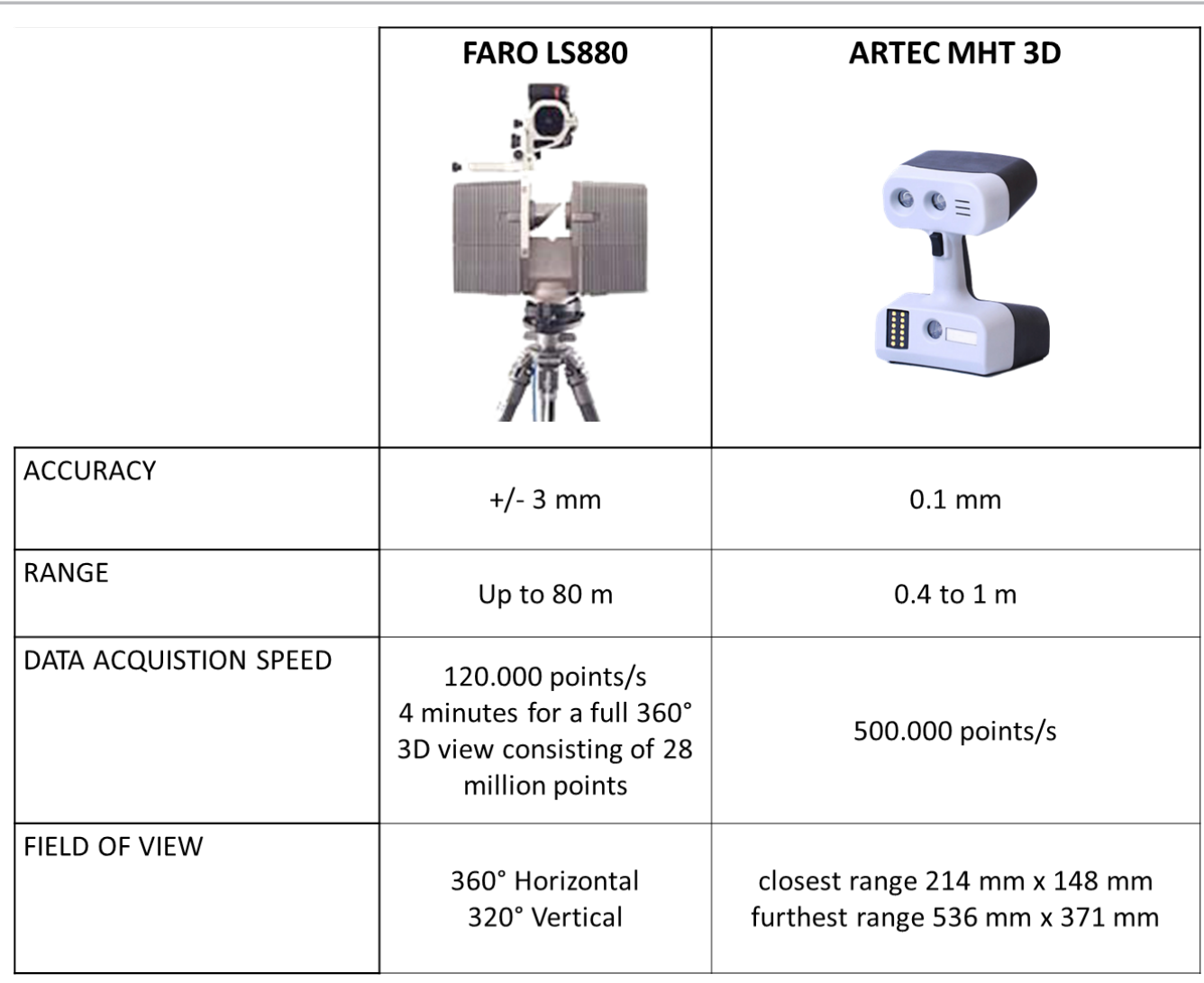


the photos taken by the Nikon camera so that, consequently, the final visualization will be poorer.

\section{Reconstruction process}

As mentioned before, this step was carried out applying three different technologies, with a specific strategy for each of them. Regarding the laser scanner, after the analysis of the area to be digitized and considering the range of $80 \mathrm{~m}$ that the Faro laser scanner offers, the scanning procedure designed consisted of positioning the scanner station in three different points that could cover the whole area. These selected positions can be observed in Figure 3.

With respect to photogrammetry, it is generally recommended to optimize the number of photos, considering an 50\% overlapping between images, in order to avoid the collapse of the workstation in charge of computing the photogrammetry, and to do it using a reasonable time. In that case, since it was known that the whole site was going to be covered by the future road, the followed strategy in this stage was to generate a bank of images with a great redundancy. The idea was to postpone the manual choice of the optimized bank of images until the 'laboratory' computing stage. Specifically, over 2500 photos were taken along the site. The technician took photos from different tripod positions and, in each position, she rotated the orientation of the camera until completing a circle and applying an approximate. Logically, the density of the tripod positions was higher in that zones where there were more archaeological rests. The Figure 4 can give an idea of the photos' distribution within a portion of the site.

Finally, the interior of the ovens digitization was carried out by iteratively scan and check the remaining parts, until they were completely acquired. At the end, we found that only a few portions in the ceiling were inaccessible to the handy scanner. Moreover, in this part of the site, a bank of images was also taken, in order to have an additional support 3D model to offer the missing information in those inaccessible portions.

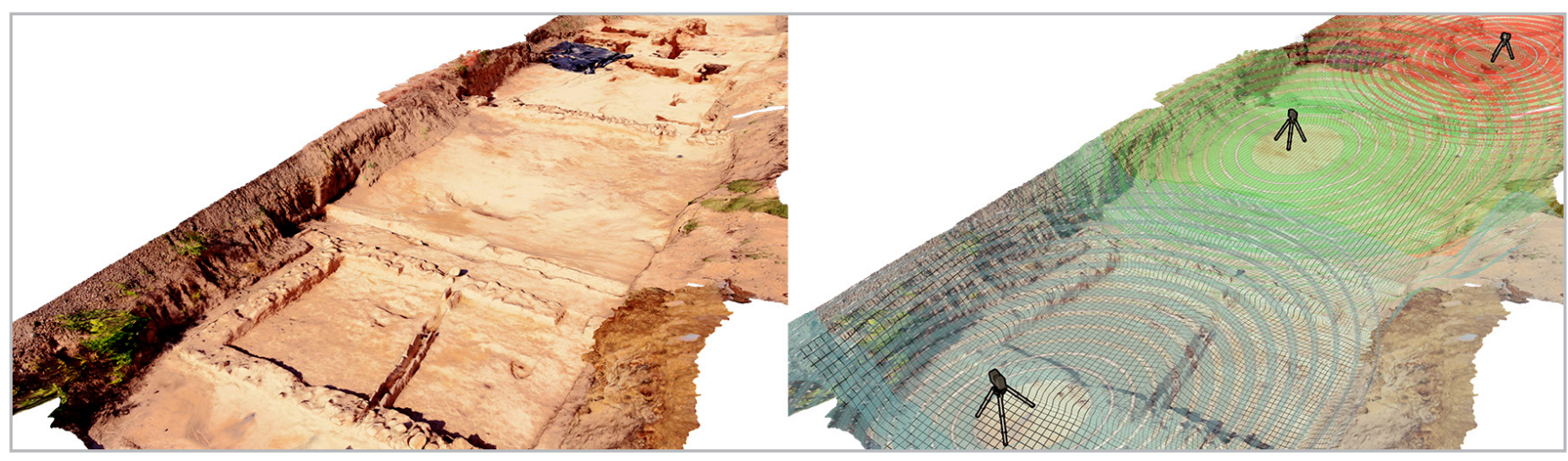

Figure 3.- Representation of the distribution of laser scanner locations to cover the whole area: on the right, the archaeological site; on the right, the three different locations that were selected

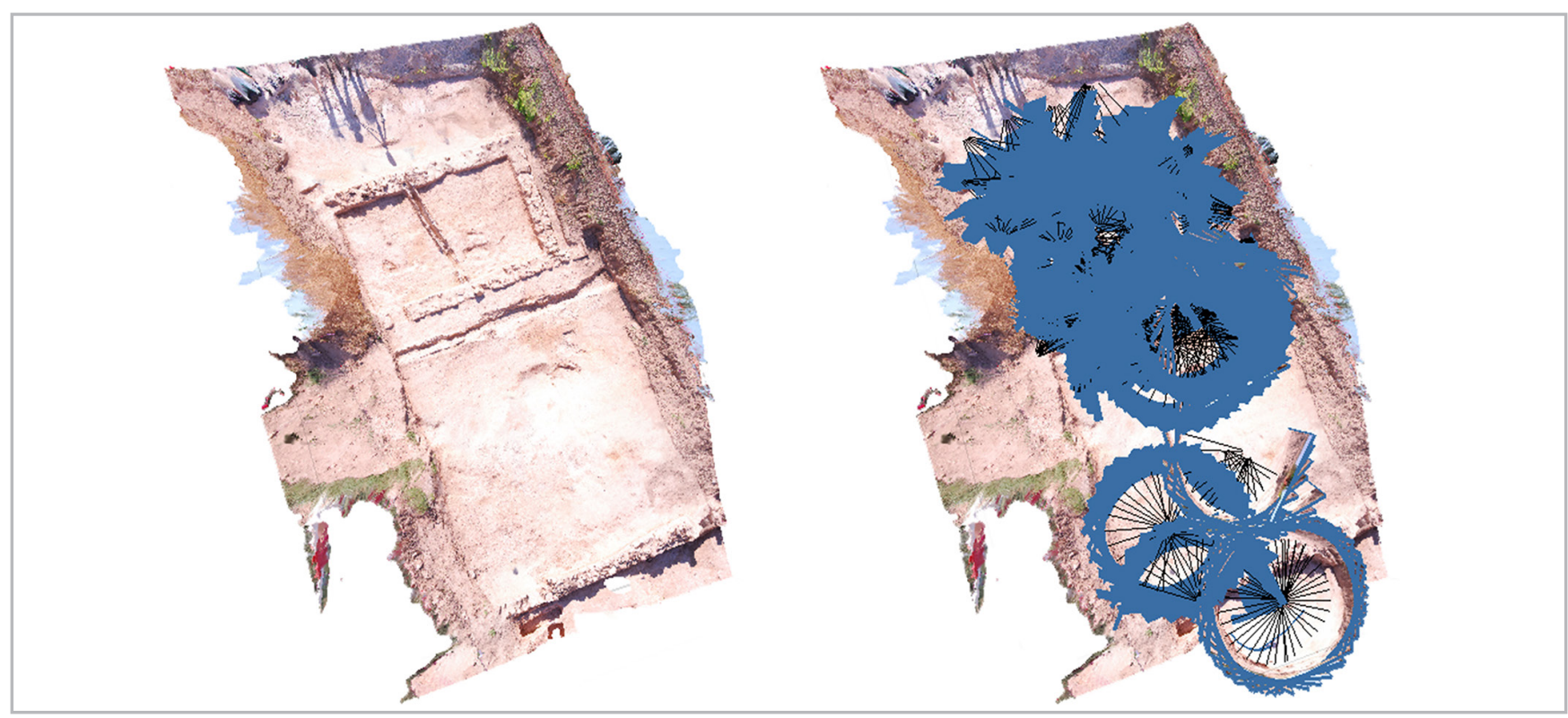

Figure 4.- Distribution of the taken photos along a portion of the site, with more density of camera positions in the areas with more rests. 
After the digitization process, three packages of 3D data obtained from the three different acquisition technologies were available, as mentioned. Such data were processed independently by means of three different specific software to generate the resulting 3D models. Figure 5 depicts the work scheme that we followed to produce the final textured 3D models starting from the acquisition stage.

Regarding the data acquired with the laser scanner, a coloured 3D point cloud with a linear accuracy of $\pm 3 \mathrm{~mm}$ at $25 \mathrm{~m}$, the required steps to obtain the 3D model are: registering of the point clouds; filtering noise and outliers; fusion, which produces a unique point of cloud; compute the mesh that fits such cloud, by triangulating the points; and calculation the texture of that mesh. Except for the triangulation and texture computation, which were carried out using Meshlab, the main software used was Faro Scene.

The structured-light scanner produces a set of textured partial meshes which are portions of the element scanned. The resolution of these acquired data is up to $0.5 \mathrm{~mm}$. These data require some consecutive standard steps: registering in the same reference system; filtering to remove errors and noise; fusion to generate a single mesh, and filling holes. Sometimes it is also necessary to retouch the final surface to equalize and make it up. Finally, it is mandatory to carry out an analysis of the final mesh and repair it to obtain a consistent surface with no errors. In our case, the first three steps were implemented with the Artec Studio software. The filling-holes process was made by applying the algorithm explained in (Pérez et al. 2008), in Matlab. The open software Meshlab was employed to analyse and repair the mesh. And, finally, the occasional surface retouching was done in the Blender software. Also, equalization was applied to the texture in some specific cases by using the GIMP software.

The last device employed was the Nikon camera, with which a vast set of photos were generated. Since it has a 10 megapixels sensor, the resolution of these images is 3872 $x$ 2592. In this case, the steps that have to be followed to generate de 3D models through photogrammetry were: aligning and pairing each subset of photos; generating the dense point clouds to produce a set of meshes; registering of all the meshes; fusion to obtain a unique surface and generation of the whole texture. Here, it is worth mentioning that photogrammetry does not produce a model as accurate as of the one obtained with the previous technologies in terms of scale. Therefore, the final model must be scaled. The scale factor is obtained by manually measuring some meaningful distances in the previous models, generated using the scanners, that is, in real scale, and applying them to the photogrammetric model. No targets were used during the scanning process, so this entails the search of common accessible points, located in sharp areas, in both models the one generated with scanner and the one generated with photogrammetry. All these steps are done, in a first approach, with the software Agisoft Metashape. Then, to get a fine adjustment, the Artec Studio software offer an interesting tool to be applied. It can compute a non-homogeneous registering process, that is, it can reorient and slightly deform a mesh with the aim of accurately fit the photogrammetry mesh to the reference one: the one generated with scanner.

In the end, a high-resolution textured model of the outdoor area is obtained from the laser scanner data. Also, a medium-low resolution textured model of the same

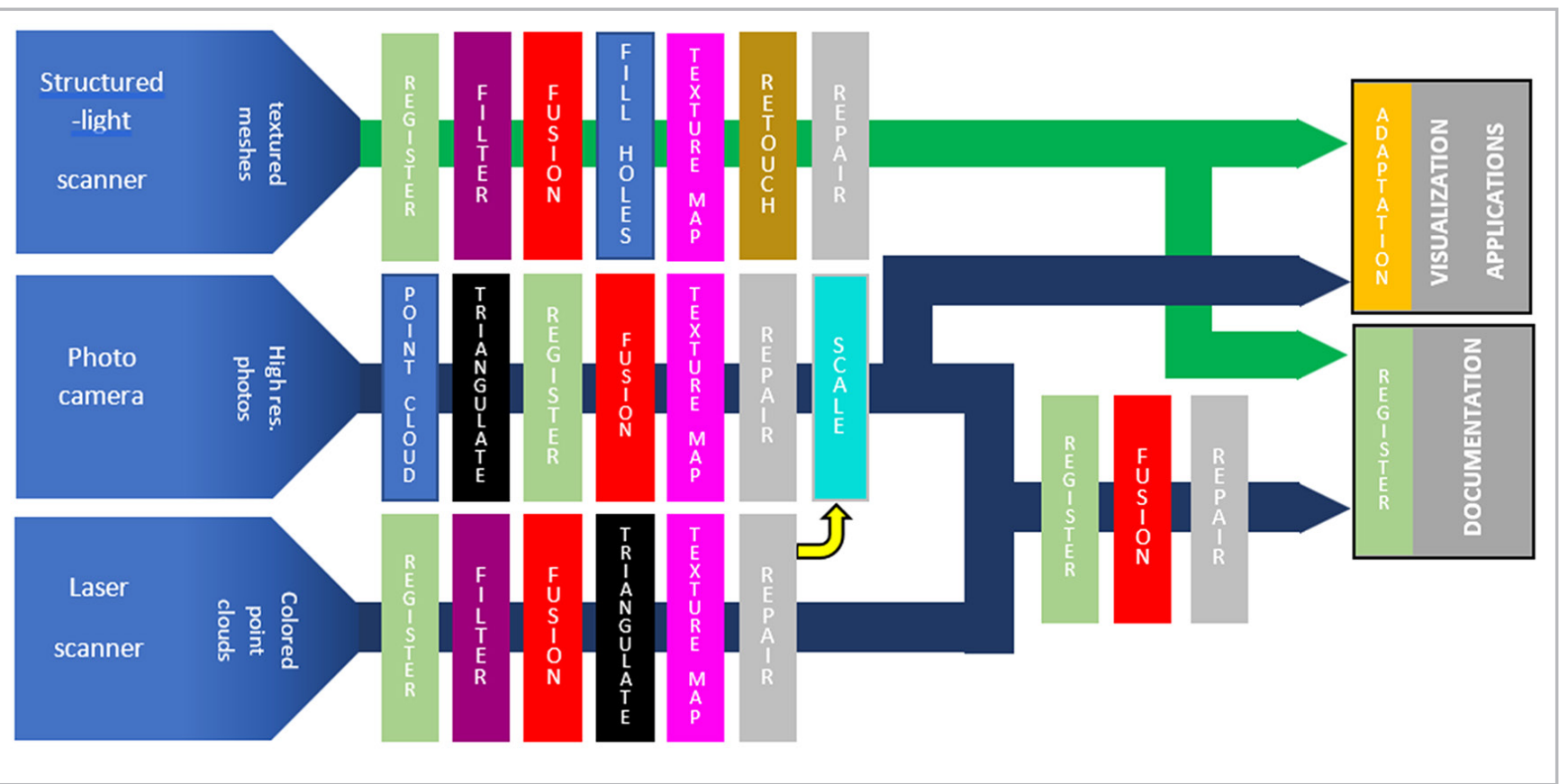

Figure 5.- Scheme of the procedure to obtain the final textured 3D models. 


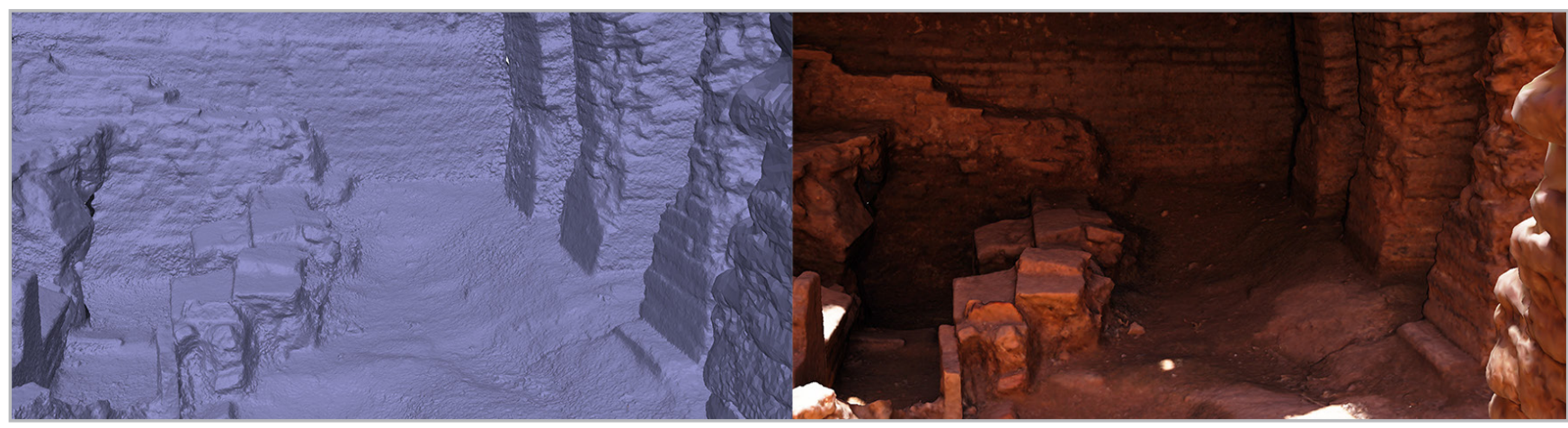

Figure 6.- Reconstructed 3D mesh (left) and 3D textured model (right) of the $\mathrm{H} 2$ oven, both of them obtained using photogrammetry techniques.

area was generated from photogrammetry techniques. The differences between these two models are the resolution of the final mesh, better in the former one, and the quality of the final texture, better in the latter model. Since the high-resolution model is going to be used for documenting the archaeological site and keep its memory, we decided to improve its texture and complete the parts that were not correctly acquired with the laser scanner using the photogrammetric model. Therefore, both models had to be registered in a common reference system, a fusion process was applied, a repairing step was also carried out and, finally, the improving of the original texture was done with Blender software, by projecting some of the Nikon camera photos onto the geometric model.

The other resulting models of the reconstruction process were those of the interiors of the kilns. These are highmedium resolution textured meshes, generated thanks to the Artec scanner, as well as to the photogrammetry techniques respectively, can be used for both documentation and visualization applications [figure 6].

At this point, there was not a complete model of the entire site available yet since we had created each part separately. For this reason, the integration of all the separated meshes to obtain a unique single mesh of the site became necessary. This integration was done by registering all the models, which entailed the positioning of the kilns in the corresponding location within the exterior model. Although both meshes had overlapping zones, a user-assisted registration was utilized.

\section{Visualization applications}

As said, two different visualization applications were designed: an immersive VR experience and a AR application.

Technically, the visualization of 3D objects in real-time has a strong dependence on both the hardware used and the number and quality (resolution of meshes and textures) of the objects to be visualized. After the digitization process, explained in previous sections, the quality of the 3D model is high. Therefore, to use the digitized models in real-time visualization it is mandatory reducing their quality, mainly in terms of the resolution of the meshes, to a specific level that can be managed by the hardware. In addition to that, the software used to design and program the visualization applications also imposes some requirements that have to be taken into consideration inescapably.

In the following subsections, the two main steps necessary to develop the visualization applications are summarized: quality reduction and data adaptation, and applications design.

\section{Quality reduction and data adaptation}

Before analysing how to carry out the reduction and adaptation, it is useful to categorize the data to be used in the applications. Thus, the following division was established: category A (laser scanner data); category B (Artec scanner data); category $C$ (photogrammetry data); and, category D (3D modelled synthetic data). We have explained above how the models belonging to these categories were created, except for the ones of category $D$. We include in that category the 3D elements modelled using Blender software that will be introduced in the visualization as decoration or as support to improve the final result.

As mentioned above, the $3 \mathrm{D}$ models belonging to categories $A$ and $B$ are generated in high resolution for the ones and in medium-low resolution the ones of category C. We modelled the 3D objects of category D in mediumlow resolution, keeping in mind the requirement of realtime visualization. Moreover, the elements of categories $A$ and $C$ represent the same area of the site, although in different resolutions. Since a high resolution is not needed in the visualization applications, we discard at this point the elements included in the category A. On the contrary, the interior of kilns was just stored in high-resolution (category B elements) and no other lower-resolution data are available. Therefore, before designing the applications, it is necessary to modify the models of categories B and C, 
regarding the type of data and their quality (resolution of mesh and resolution and size of texture). This classification and the modifications undertaken are summarized in the table shown in figure 7.

In it, by "type of 3D data" we mean how 3D and colour information is stored, i.e., whether it is a point cloud or $3 \mathrm{D}$ mesh and whether there is a texture image that stores colour information (needed for the visualization application) or not. In this case, as the elements of category A were discarded ( $X$ sign), the rest of the categories are composed of objects defined by 3D meshes, so it is not necessary to modify the type of data (hence = sign). Concerning the colour, the elements of categories B and $C$ have their own images of textures. Therefore, no modification in this sense is necessary either.

As far as quality is concerned, it is mandatory reducing it for the category B elements. However, in the case of the elements of category $C$, stored in medium-low resolution, it will depend on the hardware used. As will be explained below, two applications have been developed: a virtual reality application and an augmented reality application. The first one usually runs on desktop PCs, whereas the latter runs on mobile devices. So, the different specifications of both platforms are evident, being less powerful the mobile devices in terms of 3D representation in real-time.
In this respect, since all 3D models are used in both types of applications, a quality reduction must also be applied to the elements of category $C$.

This quality reduction is implemented in two steps: one first reduction aimed to designing the VR application and a consecutive further reduction to prepare the elements for the AR applications, i.e. to be visualized in much less powerful devices. Every step of that quality reduction consists of reducing the number of triangles composing the $3 \mathrm{D}$ meshes, reducing the quality of texture images and group them into bigger images, more optimal for the real-time (Pérez et al. 2018).

\section{Applications design}

For both the AR and the VR application we have designed proofs of concepts to visualize all the acquired data. The software employed was Unity with added libraries for the use of specific head-mounted displays (Windows Mixed Reality Lenovo Explorer) and the generation of AR mobile applications (ARCore libraries for Android).

Regarding the VR application, it allows the user to explore the entire archaeological site. It is possible to tour all the exterior area and, also, the interior of ovens. Moreover,

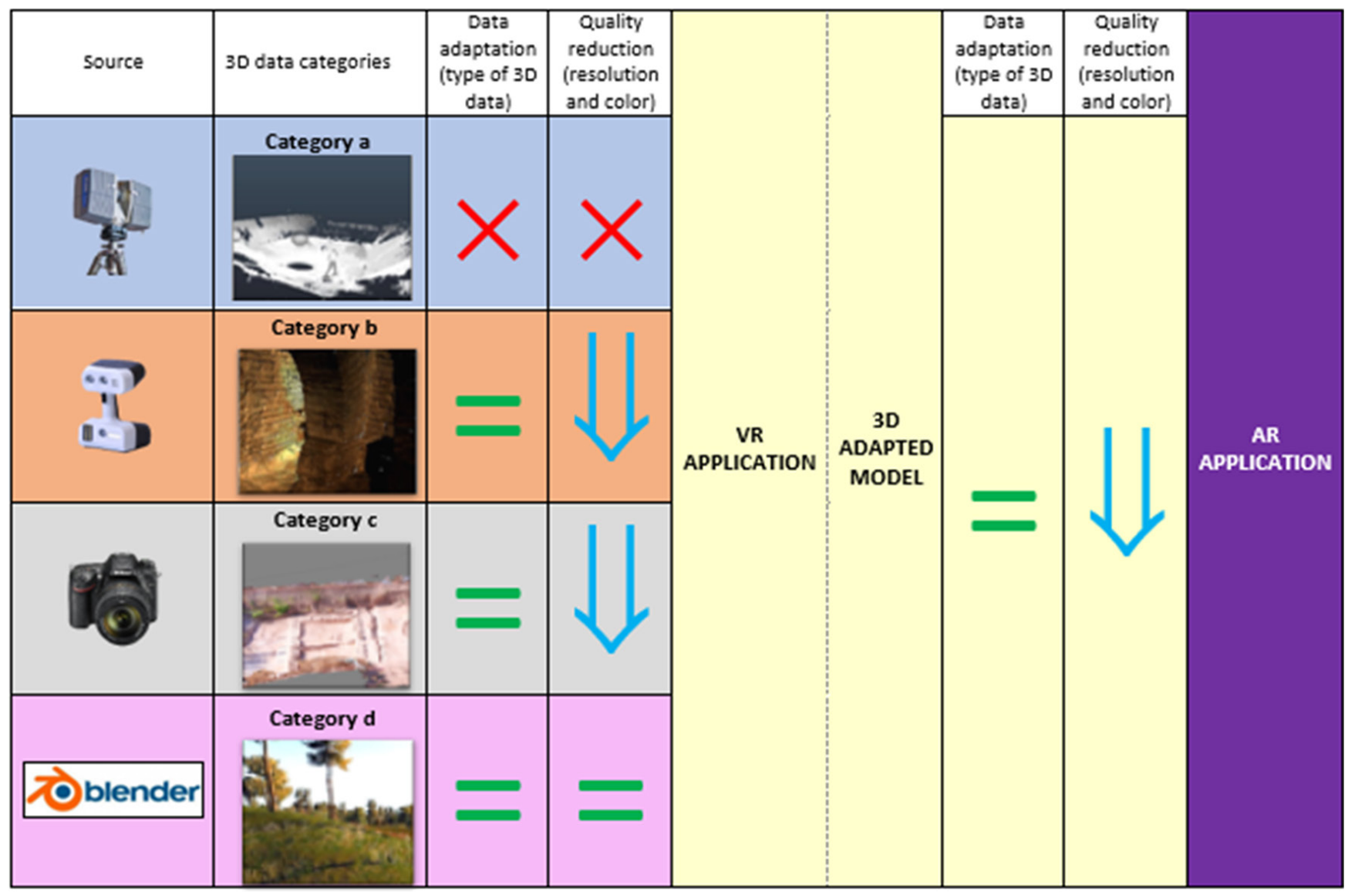

Figure 7.- Modifications undertaken regarding the type of data and the quality: " $X$ " $\Xi$ not used; " $=$ " $\Xi$ no adaptation required; “ $\Downarrow$ " $\Xi$ decrease. 


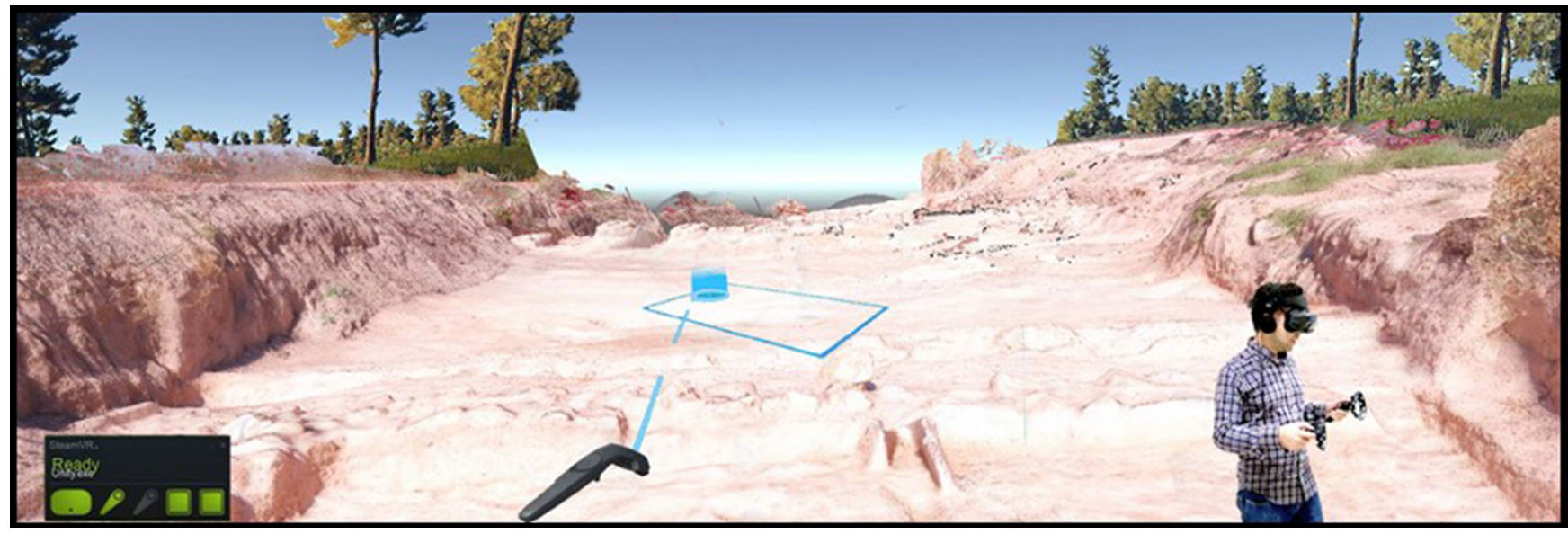

Figure 8.- Appearance of the VR experience.

some decoration elements were added to complete the environment where the site is located (vegetation, trees, sky, background) [figure 8].

In concern to the AR application, it also represents the site in real-time, although over the visualization of the mobile device's camera. This permits the instant change of point of view as the user walks. The current application does not need the use of external markers, so it is always possible to visualize the remains independently of the user's location. Additionally, to develop this application, we employed a medium-high specification mobile capable of managing an elevated number of triangles. However, it is not powerful enough to load the whole archaeological site with enough resolution of the interior of the kilns. This is why we had to split the model into portions to offer the user the possibility to load each portion separately. Specifically, we have 3 portions of the exterior area and 2 portions corresponding to the inside of the kilns [figure 9].

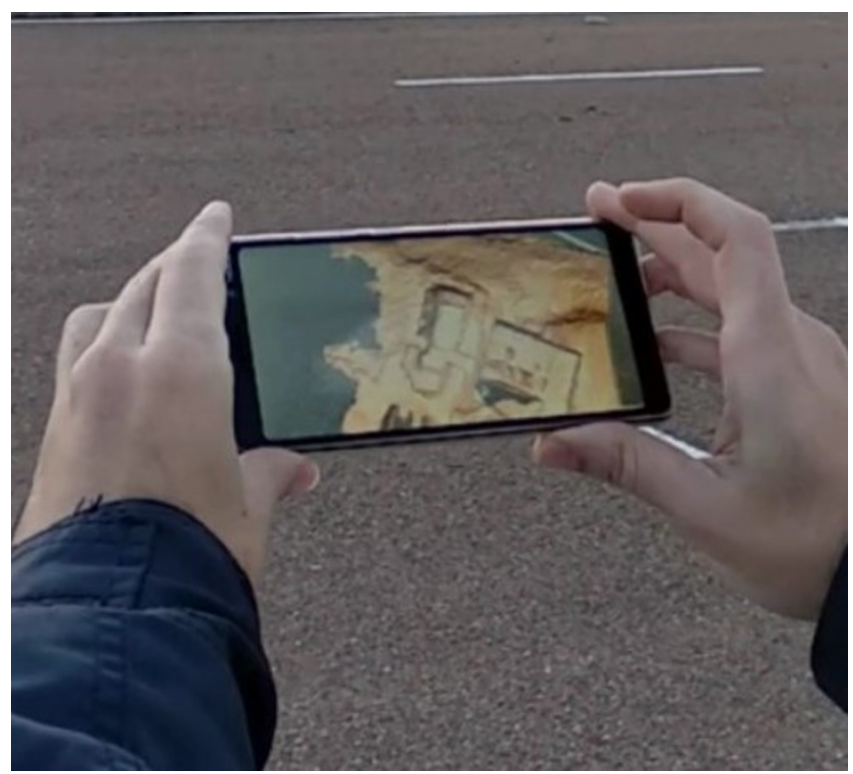

Figure 9.- AR application used in situ.

\section{Discussion}

As said above, the two applications developed are in their initial stages. Although while designing them, we carried out several tests to check some features: look, usability, delay, etc., it is obvious that an experimental study would be necessary. This study must involve different types of users, from experts in heritage to common visitors, from tourism managers to politicians.

The idea is to meet decision-makers to plan a strategy that includes the development and improvement of the applications, the testing with the public and the purchase of the necessary devices. This way, it would be possible to provide the inhabitants of Fuente del Maestre and the surroundings with some tools that allow them to know, enjoy and remember a part of its history that otherwise could fall into the oblivion. Having this type of dissemination tools would also enhance the attraction of tourism to a population that, although it was declared Historic-Artistic Site in 1998, is a little far from the usual touristic routes.

\section{Conclusions}

Sometimes it is impossible to conserve heritage for eternity. Not only because of decisions beyond the experts' criteria, but also with their consent, when the proper preservation of the remains cannot be assured. In these cases, before an announced lost, technology become a perfect ally to overcome the oblivion that the disappearance entails. The better way to preserve the cultural heritage for future generations is, in these cases, keep its memory for the people.

Throughout these pages, we have approached the application of 3D modelling to the documentation, research and dissemination of cultural heritage. Focused on the specific case of the re-covered, and so, lost Roman remains found in the nearby of Fuente del Maestre, the process to acquire 3D data of the whole site with different technologies 
was described. As said, choosing a specific technology depends on the features of the structures and the subsequent use that these 3D model generated will receive.

The procedure to merge the different meshes has been also explained, as well as the transformation of those meshes to be utilized to design Virtual and Augmented Reality applications. Afterwards, we make a small digression on how these developed VR/AR experiences are and how they can be visualized. Finally, it describes and shows both the 3D model of the site and the tentative AR application designed and explains the future work to improve the virtual experiences and make them reach the people of nearby towns so that they can know this Roman site and prevent it falls into oblivion.

\section{Acknowledgements}

This work has been supported by the project IB16162 from Junta de Extremadura and European Regional Development Fund (ERDF) "A way to make Europe". The authors would like to thank the members of the Consejería de Movilidad, Transporte e Infraestructuras (Junta de Extremadura) for their willingness and support.

\section{References}

AICARDI, I., CHIABRANDO, F., LINGUA, A.M., NOARDO, F. (2018). Recent trends in cultural heritage 3D survey: The photogrammetric computer vision approach, Journal of Cultural Heritage, 32(1): 257-266. https://doi.org/10.1016/j.culher.2017.11.006

ANDREU, J., SERRANO, P. (2019). "Contributions of the digital photogrammetry and 3D modelling of Roman inscriptions to the reading of damaged tituli: An example from the Hispania Tarraconensis (Castiliscar, Saragossa)", Digital Applications in Archaeology and Cultural Heritage, 12. https://doi.org/10.1016/j. daach.2019.e00091

ARGYRIOU, L., ECONOMOU, D., BOUKI, V. (2020). “Design methodology for 360 degrees immersive video applications: the case study of a cultural heritage virtual tour", Personal and Ubiquitous Computing. https://doi.org/10.1007/s00779-020$\underline{01373-8}$

AZUMA, R.T. (1997). "A Survey of Augmented Reality", Presence: Teleoperators and Virtual Environments, 6 (4): 355-385.

BEKELE, M. K., PIERDICCA, R., FRONTONI, E., MALINVERNI, E. S., GAIN, J. (2018). "A Survey of Augmented, Virtual, and Mixed Reality for Cultural Heritage", Journal on Computing and Cultural Heritage, 11 (2): 1-36. https://doi.org/10.1145/3145534

CASTRIOTA, B. (2019). "Authenticity, Identity, and Essentialism: Reframing Conservation Practice". In: What is the essence of conservation? Materials for a discussion. F. Mairesse \& R. F. Peters (Eds.). ICOFOM: París: 39-48.
COZZANI, G., POZZI, F., DAGNINO, F.M., KATOS, A.V., KATSOULI, E.F. (2017). "Innovative technologies for intangible cultural heritage education and preservation: the case of i-Treasures", Personal and Ubiquitous Computing 21(2): 253-265. https://doi.org/10.1007/ s00779-016-0991-z

DESVALLÉES, A., MAIRESSE, F. (Eds.) (2010). Key concepts of museology. Armand Colin: París.

HÖLLING, H. (2017). "The technique of conservation: on realms of theory and cultures of practice, Journal of the Institute of Conservation, 40 (2): 87-96.

ICOMOS (1994). The Nara document on authenticity.

ICOMOS (2004). International Charters for Conservation and Restoration. Monuments and sites I. ICOMOS: München.

MAH, O. B. P., YAN, Y., TAN, J. S. Y., TAN, Y-X., TAY, G. Q. Y., CHIAM, D. J., WANG, Y-C., DEAN, K., FENG, C.-C. (2019). "Generating a virtual tour for the preservation of the (in)tangible cultural heritage of Tampines Chinese Temple in Singapore", Journal of Cultural Heritage, 39: 202-211. https://doi.org/10.1016/j. culher.2019.04.004

MERCHÁN, M.J.; MERCHÁN, P.; SALAMANCA, S.; PÉREZ, E.; NOGALES, T. (2019). “Digital fabrication of cultural heritage artwork replicas. In the search for resilience and socio-cultural commitment", Digital Applications in Archaeology and Cultural Heritage, 15: e00125. https://doi.org/10.1016/j.daach.2019. $\underline{\mathrm{e} 00125}$

NIQUET, N.D., MAS-BARBERÀ, X. (2018). “El registro 3D como medio para el análisis y difusión del patrimonio escultórico. El caso de la escultura en cera del Écorché", Ge-conservación, 13: 5-16. https://doi.org/10.37558/gec.v13i0.551

NJEREKAI, C. (2019). "An application of the virtual reality 360 degrees concept to the Great Zimbabwe monument", Journal of Heritage Tourism. https://doi.org/10.1080/174387 $\underline{3 X .2019 .1696808}$

PASCUAL, J. (1999). “Fuente del Maestre: Dos mil años de historia”. En: Fuente del Maestre. 100 años de ciudad, 2000 años de historia. Pascual, J. (coord.). Excmo. Ayto. Fuente del Maestre: 13-53.

PÉREZ, E., SALAMANCA, S., MERCHÁN, P., ADÁN, A., CERRADA, C., CAMBERO, I. (2008). "A Robust Method for Filling Holes in 3D Meshes Based on Image Restoration". In: Advanced Concepts for Intelligent Vision Systems, 10th International Conference, ACIVS 2008, Bourennane, S. et al. (Eds.). Springer: 742-751. https://doi. org/10.1007/978-3-540-88458-3 67

PÉREZ, E., MERCHÁN, M.J., MORENO-RABEL, M.D., MERCHÁN, P., SALAMANCA, S. (2018). "Touring the Forum Adiectum of Augusta Emerita in a virtual reality experience". In: Digital Heritage. Progress in Cultural Heritage: Documentation, Preservation, and Protection, loannides, M. et al. (Eds.). Springer: 548-559. 
PEREZ, E, MERCHÁN, M.J., SALAMANCA, S. AND MERCHÁN, P. (2019). "Virtual reality to allow wheelchair users touring complex archaeological sites in a realistic manner. Towards their actual social integration", International Archives of the Photogrammetry, Remote Sensing and Spatial Information Sciences, XLII-2/W9: 597604. https://doi.org/10.5194/isprs-archives-XLII-2-W9-597-2019

RUIZ BAZÁN, I., VITA, G.E.E. (2017). "The utility of the application of new three-dimensional technologies for the study and dissemination of heritage from a historical technical perspective: case studies", Geconservación, 11:208-203. https://doi.org/10.37558/gec.v11i0.480

RUIZ TORRES, D. (2017). El uso de tecnologías digitales en la conservación, análisis y difusión del patrimonio cultural. Acción Cultural Española (AC/E).

SÁNCHEZ-APARICIO, L. J., MORENO-BLANCO, R., MARTÍN-JIMÉNEZ, J. A., RODRÍGUEZ-GONZÁLVEZ, P., MUÑOZ-NIETO, A. L., AND GONZÁLEZ-AGUILERA, D. (2019). "Smartwall: A new web-based platform for the valorization of the medieval wall of Ávila", Int. Arch. Photogramm. Remote Sens. Spatial Inf. Sci., XLII-2/W15: 1055-1062. https://doi.org/10.5194/isprs-archives-XLII-2-W15-1055-2019

SÁNCHEZ GONZÁLEZ, L.M. (2019). "A high-roman-empire alpharera industry between Villafranca de los Barros and la Fuente del Maestre", El Hinojal, Revista de Estudios del Muvi, 12: 8-21.

TAIT, E., LAING, R., GRINNALL, A., BURNETT, S., ISAACS, J. (2016). "(Re)presenting heritage: laser scanning and $3 D$ visualisations for cultural resilience and community engagement", Journal of Information Science, 42(3): 420-433. https://doi. org/10.1177/0165551516636306

TUCCI, G, BONORA, V, CONTI, A, FIORINI, L. (2017). “High-quality 3D models and their use in a cultural heritage conservation project", The International Archives of the Photogrammetry, Remote Sensing and Spatial Information Sciences, Volume XLII-2/W5: 687693. https://doi.org/10.5194/isprs-archives-XLII-2-W5-687-2017

ZHOU, M., GENG, G., WU, Z. (2012). Digital Preservation Technology for Cultural Heritage. Springer.

\section{Author/s}

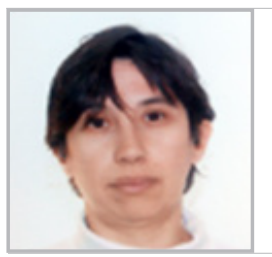

\section{María José Merchán}

mjmerchan@unex.es

School of Industrial Engineering of the University de Extremadura, Badajoz, Spain

Works as a researcher at the School of Industrial Engineering of the University de Extremadura, Badajoz, Spain. She works on the application of technologies for problem-solving in the field of Cultural Heritage. She collaborates with the National Museum of Roman Art and has taken part in several national and international R \& D projects. She has generated more than 20 technical contributions on prestigious journals and conferences.

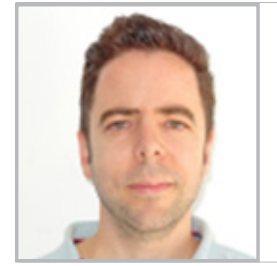

\section{Emiliano Pérez}

emilianoph@unex.es

School of Industrial Engineering of the University de Extremadura, Badajoz, Spain

Is an Associate Lecturer at the School of Industrial Engineering of the University de Extremadura, Badajoz, Spain. He has worked as researcher in 5 R\&D projects and has made more than 20 contributions in conferences and journals. He focuses his research on 3D Computer Vision and Virtual Reality: pattern recognition, modelling, representation and reconstruction of 3D objects, 3D sensors applied on cultural heritage, virtual simulation. 